\title{
Future perspectives in diabesity treatment: Semaglutide, a glucagon-like peptide 1 receptor agonist (Review)
}

\author{
MARIANA CORNELIA TILINCA ${ }^{1,2}$, ROBERT AURELIAN TIUCA ${ }^{3,4}$, \\ CRISTINA NICULAS ${ }^{5}$, ANDREEA VARGA $^{6,7}$ and IOAN TILEA ${ }^{1,7}$ \\ ${ }^{1}$ Department of Internal Medicine, 'George Emil Palade' University of Medicine, Pharmacy, Science and Technology of \\ Targu Mures, 540142 Targu Mures; ${ }^{2}$ Compartment of Diabetology, Emergency Clinical County Hospital, 540136 Targu Mures; \\ ${ }^{3}$ Department of Endocrinology, 'George Emil Palade' University of Medicine, Pharmacy, Science and Technology of \\ Targu Mures, 540142 Targu Mures; ${ }^{4}$ Department of Endocrinology, Mures County Clinical Hospital, 540139 Targu Mures; \\ ${ }^{5}$ Richter Pharmacy 7, 400129 Cluj Napoca; ${ }^{6}$ Department of Family Medicine, 'George Emil Palade' University of Medicine, \\ Pharmacy, Science and Technology of Targu Mures, 540142 Targu Mures; ${ }^{7}$ Department of Cardiology II,
}

Emergency Clinical County Hospital, 540042 Targu Mures, Romania

Received May 5, 2021; Accepted July 27, 2021

DOI: $10.3892 /$ etm.2021.10601

\begin{abstract}
Given their endemic prevalence in the past decades, obesity and type 2 diabetes mellitus (T2DM) have become a major sanitary burden with an important economic impact. Novel treatment options have been designed with the aim of reducing the numerous complications associated with these metabolic disorders, as well as reducing morbidity and mortality and improving the quality of life of those who suffer from these disorders. Glucagon-like peptide 1 receptor agonists (GLP-1 RAs) are among the most modern therapeutics that target 'diabesity', a term used to describe the pathophysiological link between obesity and T2DM. Their glucose-lowering effects are mainly attributed to glucose-dependent insulin secretion, glucagon inhibition and decreased gastric emptying. Given the effects on the central nervous system, GLP-1 RA usage may lead to body weight reduction. GLP-1 RAs are classified based on their pharmacokinetic properties as short- and long-acting agents, with both types being administered by subcutaneous injection. The latest agent from this drug class approved for use in T2DM is semaglutide, a long-acting compound that is the only GLP-1 RA available as an oral pill. The present narrative review highlights the most recently published data on the effects and safety of semaglutide in diabetic obesity, also emphasizing its cardiovascular benefits and potential side effects. In addition, an overview of the role of semaglutide in the treatment of non-diabetic obesity is provided.
\end{abstract}

Correspondence to: Dr Robert Aurelian Tiuca, Department of Endocrinology, Mures County Clinical Hospital, 38 Gheorghe Marinescu Street, 540139 Targu Mures, Romania

E-mail: tiuca.robert@gmail.com

Key words: semaglutide, glucagon-like peptide 1, type 2 diabetes mellitus, obesity, diabesity

\section{Contents}

1. Introduction

2. GLP-1-biological effects and development of GLP-1 RAs

3. Semaglutide in diabesity and non-diabetic obesity

4. Semaglutide-side effects and cautions

5. Future considerations

6. Conclusions

\section{Introduction}

Obesity is a metabolic disease with increasing prevalence over the past decades, becoming an important economic and health care burden (1). In 2016, the World Health Organization estimated that worldwide more than 650 million adults were obese (2). Obesity is associated with multiple chronic comorbidities, being the leading risk factor for type 2 diabetes mellitus (T2DM) (3).

The term 'diabesity' describes the pathophysiologic link between obesity and T2DM and was first introduced by Sims et al (4) in 1973. In 2019, the International Diabetes Federation estimated that 463 million individuals worldwide have diabetes, projecting that by 2045 , there will be $>700$ million cases (5). The presence of 'diabesity' enhances the risk of developing cardiovascular disease, thus increasing morbidity and mortality (6,7). Managing diabesity is challenging, considering that numerous frequently used antidiabetic agents, such as sulfonylureas, meglitinides, thiazolidinediones and insulin, may lead to weight gain and therefore cause a vicious cycle (8).

One of the most modern drug classes available that is able to achieve both glycemic control and weight loss are glucagon-like peptide 1 (GLP-1) receptor agonists (GLP-1 RAs). GLP-1 RAs are widely used as a glucose-lowering therapy with weight reduction and cardiovascular benefits in T2DM, having also beneficial effects in non-diabetic obesity as a weight loss 
adjuvant therapy $(9,10)$. The present narrative review aimed to highlight the effects of semaglutide, the most recently approved GLP-1 RA for T2DM as indicated in the existing literature, and to emphasize the emerging role of semaglutide in managing diabesity and non-diabetic obesity.

\section{GLP-1-biological effects and development of GLP-1 RAs}

Biological effects. GLP-1 is an incretin hormone secreted in a biphasic pattern by the neuroendocrine L cells in the distal ileum and colon after consumption of nutrients, particularly glucose and other carbohydrates $(11,12)$. It has a short elimination half-life (1-2 $\mathrm{min}$ ) due to proteolysis by dipeptidyl peptidase IV and renal elimination (12). GLP-1 receptors are expressed in numerous organs, mainly occurring in the pancreas, central nervous system (hypothalamus) and the gastrointestinal tract, but also in the heart and kidneys (12). GLP-1 stimulates insulin secretion from the $\beta$-pancreatic cells in a glucose-dependent manner, also promoting $\beta$-pancreatic cell survival and proliferation $(13,14)$. Furthermore, GLP-1 reduces glucagon secretion by $\alpha$-pancreatic cells through complex endocrine mechanisms, which include somatostatin stimulation and insulinotropic effects on the $\beta$-pancreatic cells (12). By slowing down gastric emptying, GLP-1 further reduces blood glucose and appetite (15). This effect on appetite is not only attributed to the delayed gastric emptying but also to its influence on the hypothalamus as a neurotransmitter, particularly on the lateral hypothalamus, and the paraventricular and arcuate nucleus $(16,17)$. Other effects of endogenous GLP-1 include reduction in systolic blood pressure, increased myocardial contraction, improved endothelial vasodilation, increased glycogen storage, improved lipid profile, diuresis and natriuresis induction (18-21).

Development of GLP-1 RAs. At present, six injectable (subcutaneous) GLP-1 RAs and one oral formulation are available in Europe for T2DM treatment. Based on their pharmacological properties, GLP-1 RAs are classified into short- or long-acting agents. Short-acting GLP-1 RAs include exenatide standard-release (Byetta) and lixisenatide (Lyxumia). Their major mechanism of action is based on slowing gastric emptying and lowering postprandial glucose. Long-acting GLP-1 RAs include exenatide modified-release (Bydureon), liraglutide (Victoza), dulaglutide (Trulicity) and semaglutide (Ozempic). Compared to short-acting compounds, long-acting agents have a mechanism of action that mainly comprises stimulating insulin secretion and inhibiting glucagon release, thus influencing both postprandial and fasting glucose. The posology of GLP-1 RAs in T2DM is illustrated in Table I (22,23).

Liraglutide was the first antidiabetic treatment approved as a weight reduction drug in non-diabetic obesity. Sold under the name of Saxenda, liraglutide at a dose of $3.0 \mathrm{mg}$ once daily was approved by both Food and Drug Administration in 2014 and the European Medicines Agency in 2015 for long-term weight management (24).

\section{Semaglutide in diabesity and non-diabetic obesity}

Excess weight, particularly when associated with visceral fat, increases the risk of insulin resistance, metabolic syndrome and T2DM $(25,26)$. The link between excess weight and T2DM supposably lies in the inflammatory state associated with excess adipose tissue. Several pro-inflammatory mediators, such as tumor necrosis factor- $\alpha$, interleukin- 6 and complement component 3 , along with fatty-acid lipotoxicity inhibit intracellular insulin signaling, which may lead to pancreatic $\beta$-cell dysfunction and subsequently to T2DM (27). When a new diagnosis of T2DM is made, it is crucial to educate the patient regarding the importance of a healthy lifestyle, which includes avoiding excess calories (particularly high-glycemic-index carbohydrates) and increasing physical activity to prevent cardiovascular and metabolic complications. Nicola et al (28) noted a significantly higher low-density lipoprotein cholesterol, hypertriglyceridemia, low high-density lipoprotein cholesterol and a higher prevalence of micro- and macroalbuminuria in hypertensive diabetic patients.

The American Diabetes Association recommends metformin as the first-line drug for T2DM therapy, if not contraindicated (10). GLP-1 RAs are known to lower blood glucose by stimulating insulin production in the pancreatic $\beta$-cells and inhibiting glucagon release by the pancreatic $\alpha$-cells, combined with slowing gastric emptying and reducing appetite and food consumption (29). Therefore, given their beneficial effects on glucose metabolism and weight loss potential, GLP-1 RAs are currently recommended as a second-line therapy in T2DM. Furthermore, their action of increasing insulin production and lowering glucagon action is tailored in a glucose-dependent manner, thus posing a low risk of hypoglycemia and making them one of the most effective and safe options when a more intensive antidiabetic treatment is required (30).

Semaglutide (Ozempic) is a long-acting GLP-1 RA and its administration is once-weekly subcutaneously at doses of 0.5 and $1.0 \mathrm{mg}$, with $0.25 \mathrm{mg} /$ week being the initiation dose for the first 4 weeks. The safety and efficacy of semaglutide was investigated in the Semaglutide Unabated Sustainability in Treatment of Type 2 Diabetes (SUSTAIN) clinical trial program. A summary of the major results from the SUSTAIN clinical program is provided in Table II.

Semaglutide as a blood glucose-lowering agent. SUSTAIN-1 was a phase IIIa clinical trial that compared the safety and efficacy of semaglutide $(0.5$ and $1.0 \mathrm{mg})$ over the course of 30 weeks vs. placebo in patients with T2DM that had no prior drug therapy, only diet and exercise interventions. Compared to the placebo, both doses of semaglutide produced a significant reduction in glycated hemoglobin (HbA1c) [-1.45\% with semaglutide $0.5 \mathrm{mg}$ vs. $-1.55 \%$ with semaglutide $1.0 \mathrm{mg}$ vs. $-0.2 \%$ with placebo; the estimated treatment difference (ETD) for semaglutide $0.5 \mathrm{mg}$ vs. placebo was $-1.43 \%$ and the ETD for semaglutide $1.0 \mathrm{mg}$ vs. placebo was $-1.53 \%$; $\mathrm{P}$ for both doses of semaglutide vs. placebo <0.0001] (31).

The SUSTAIN-2 clinical trial compared semaglutide 0.5 and $1.0 \mathrm{mg}$ with sitagliptin $100 \mathrm{mg}$ over the course of 56 weeks in patients with T2DM inadequately controlled with metformin, thiazolidinediones or both. HbA1c reduction was greater with both doses of semaglutide vs. sitagliptin (-1.3\% with $0.5 \mathrm{mg}$ semaglutide vs. $-1.6 \%$ with $1.0 \mathrm{mg}$ semaglutide vs. $-0.5 \%$ with $100 \mathrm{mg}$ of sitagliptin; ETD $-0.77 \%$ with semaglutide $0.5 \mathrm{mg}$ and $-1.06 \%$ with semaglutide $1.0 \mathrm{mg}$; 
Table I. Posology of GLP-1 RA in type 2 diabetes mellitus.

\begin{tabular}{|c|c|c|}
\hline GLP-1 RA & Structure & Posology \\
\hline Exenatide standard-release & Exenatide-4 derivative & $\begin{array}{l}5 \mu \mathrm{g} \text { twice daily for first month, then increase to } 10 \mu \mathrm{g} \text { twice daily, before } \\
\text { meals }\end{array}$ \\
\hline Lixisenatide & Exenatide-4 derivative & $\begin{array}{l}10 \mu \mathrm{g} \text { once daily first two weeks, then increase to } 20 \mu \mathrm{g} \text { once daily, } \\
\text { before meals }\end{array}$ \\
\hline Exenatide modified-release & Exenatide-4 derivative & $2 \mathrm{mg}$ once weekly, with or without meals \\
\hline Liraglutide & Modified human GLP-1 & $\begin{array}{l}0.6 \mathrm{mg} \text { once daily for first week, then increase to } 1.2 \mathrm{mg} \text { once daily } \\
\text { (further increase up to } 1.8 \mathrm{mg} \text { if poor glucose control), with or without } \\
\text { meals }\end{array}$ \\
\hline Dulaglutide & Modified human GLP-1 & $\begin{array}{l}0.75 \mathrm{mg} \text { once weekly in monotherapy }(1.5 \mathrm{mg} \text { once weekly as add-on } \\
\text { therapy), with or without meals }\end{array}$ \\
\hline Semaglutide & Modified human GLP-1 & $\begin{array}{l}0.25 \mathrm{mg} \text { once weekly for first month, then increase to } 0.5 \mathrm{mg} \text { once } \\
\text { weekly for at least one month (further increase up to } 1 \mathrm{mg} \text { in case of } \\
\text { poor glycemic control), with or without meals }\end{array}$ \\
\hline Semaglutide (oral) & Modified human GLP-1 & $\begin{array}{l}3 \mathrm{mg} \text { once daily for one month, then increase to } 7 \mathrm{mg} \text { once daily for at } \\
\text { least one month (further increase up to } 14 \mathrm{mg} \text { in case of poor glycemic } \\
\text { control), before meals }\end{array}$ \\
\hline
\end{tabular}

GLP-1 RA, glucagon-like peptide 1 receptor agonist.

P for both doses of semaglutide vs. sitagliptin $<0.0001$ for non-inferiority and superiority) (32). Semaglutide $1.0 \mathrm{mg}$ was compared with once-weekly exenatide in the SUSTAIN-3 clinical trial, which was performed over the course of 56 weeks on 813 adults with T2DM on previous oral antidiabetic agents. A reduction in HbA1c of $1.5 \%$ with semaglutide and $0.9 \%$ with exenatide was noted (ETD, 0.62\%; P<0.0001 for noninferiority and superiority for semaglutide vs. exenatide once-weekly) (33).

SUSTAIN-4 assessed the safety and efficacy of semaglutide compared to insulin glargine in patients with T2DM inadequately controlled with metformin (with or without sulfonylureas). At week 30, semaglutide at 0.5 and $1.0 \mathrm{mg}$ achieved greater $\mathrm{HbA1c}$ reductions than insulin glargine (1.21 vs. 1.64 vs. $0.83 \%$; ETD, $-0.38 \%$ with semaglutide $0.5 \mathrm{mg}$ and $-0.81 \%$ with semaglutide $1.0 \mathrm{mg}$ with ETD; $\mathrm{P}<0.0001$ for ETD for both doses of semaglutide vs. insulin glargine) (34). In the SUSTAIN-5 clinical trial, semaglutide was investigated as an add-on vs. placebo in patients with T2DM on basal insulin, with or without metformin. At week 30, HbA1c exhibited a significant reduction of 1.4 and $1.8 \%$ with semaglutide 0.5 and $1.0 \mathrm{mg}$, respectively, vs. $0.1 \%$ with placebo (P for both doses of semaglutide vs. placebo <0.0001) (35). The SUSTAIN-7 clinical trial proved the superiority of 0.5 and $1.0 \mathrm{mg}$ semaglutide in improving the mean HbA1c when compared to dulaglutide 0.75 and $1.5 \mathrm{mg}$. Semaglutide $0.5 \mathrm{mg}$ reduced the mean HbA1c by 1.5 vs. $1.1 \%$ with dulaglutide $0.75 \mathrm{mg}$. Furthermore, $1.0 \mathrm{mg}$ of semaglutide produced a reduction of $1.8 \%$ in $\mathrm{HbA} 1 \mathrm{c}$ vs. $1.4 \%$ with dulaglutide $1.5 \mathrm{mg}(36)$.

SUSTAIN-8 compared once-weekly semaglutide $1.0 \mathrm{mg}$ with once-daily canagliflozin $300 \mathrm{mg}$ in patients with T2DM inadequately controlled with metformin. Semaglutide was superior to canagliflozin in reducing HbA1c (ETD, -0.49\%;
$\mathrm{P}<0.0001)$ (37). In SUSTAIN-9, the efficacy and safety of semaglutide were assessed when added to a sodium glucose cotransporter-2 (SGLT-2) inhibitor in patients with T2DM with poor glycemic control. Semaglutide in addition to a SGLT-2 inhibitor significantly reduced HbA1c (ETD, -1.42\%; $\mathrm{P}<0.0001)$ compared with placebo. Semaglutide added to a SGLT-2 inhibitor was well tolerated with significant improvements in glycemic control (38).

In SUSTAIN-10, semaglutide (1.0 mg/week) was compared with liraglutide $(1.2 \mathrm{mg} /$ day $)$ in subjects with T2DM treated with 1-3 oral antidiabetic drugs. A total of 577 subjects were randomized to receive either semaglutide or liraglutide. Patients receiving semaglutide had a superior reduction in HbA1c (ETD, -0.69\%; P<0.0001). Both treatments had similar safety profiles, with semaglutide having a higher frequency of gastrointestinal reactions compared to liraglutide (43.9 vs. $38.3 \%)$ (39).

Semaglutide andbodyweightreduction benefits.In SUSTAIN-1, a marked body weight loss was observed with both doses of semaglutide when compared to placebo. Specifically, with semaglutide at 0.5 and $1.0 \mathrm{mg}$, a weight reduction of 3.73 and $4.53 \mathrm{~kg}$ $\mathrm{kg}$ was achieved, respectively, while the placebo had an insignificant loss of $0.98 \mathrm{~kg}$ (ETD vs. placebo, -2.75 and $-3.56 \mathrm{~kg}$ with semaglutide 0.5 and $1.0 \mathrm{mg}$, respectively; $\mathrm{P}$ for both doses of semaglutide vs. placebo <0.0001) (31). In SUSTAIN-2, at week 56 , a weight loss of $4.3 \mathrm{~kg}$ with semaglutide $0.5 \mathrm{mg}$ and $6.1 \mathrm{~kg}$ with semaglutide $1.0 \mathrm{mg}$, and $1.9 \mathrm{~kg}$ with sitagliptin $100 \mathrm{mg}$ was achieved (ETD, $-2.35 \mathrm{~kg}$ with semaglutide $0.5 \mathrm{mg}$ and $-4.20 \mathrm{~kg}$ with semaglutide $1.0 \mathrm{mg}$ vs. sitagliptin; $\mathrm{P}$ for both doses of semaglutide vs. sitagliptin $<0.0001$, with superiority of sitagliptin) (32).

The SUSTAIN-3 trial indicated that semaglutide-treated subjects achieved a greater weight reduction when compared 
Table II. Summary of clinical trials from the SUSTAIN program.

Clinical trial Aim Main results

SUSTAIN-1 To assess the safety and efficacy of semaglutide vs. placebo in T2DM patients without prior drug therapy

SUSTAIN-2 To assess the safety and efficacy of semaglutide vs. sitagliptin in T2DM patients with poor control on metformin, thiazolidinediones or both

SUSTAIN-3 To assess the safety and efficacy of semaglutide vs. once-weekly exenatide in T2DM patients on previous oral antidiabetic agents

SUSTAIN-4 To assess the safety and efficacy of semaglutide vs. insulin glargine in T2DM patients with poor control on metformin, with or without sulfonylureas

SUSTAIN-5 To investigate the superiority of semaglutide vs. placebo in T2DM patients on basal insulin, with or without metformin

SUSTAIN-6 To investigate the cardiovascular safety of semaglutide in T2DM

SUSTAIN-7 To assess the safety and efficacy of semaglutide vs. dulaglutide in T2DM patients with poor control on metformin

SUSTAIN-8 To assess the safety and efficacy of semaglutide vs. canagliflozin in T2DM patients with poor control on metformin

SUSTAIN-9 To assess the safety and efficacy of semaglutide when added to a SGLT-2 inhibitor in patients with poorly controlled T2DM

SUSTAIN-10 To assess the safety and efficacy of semaglutide vs. liraglutide in T2DM patients on 1-3 oral antidiabetic agents
Semaglutide 0.5 and $1.0 \mathrm{mg}$ significantly reduced $\mathrm{HbA} 1 \mathrm{c}$ vs. placebo (-1.45 vs. -1.55 vs. $-0.2 \%)$; semaglutide 0.5 and $1.0 \mathrm{mg}$ significantly reduced body weight vs. placebo $(-3.73$ vs. -4.53 vs. $-0.98 \mathrm{~kg})$

Semaglutide 0.5 and $1.0 \mathrm{mg}$ achieved a greater $\mathrm{HbA} 1 \mathrm{c}$ reduction vs. sitagliptin $100 \mathrm{mg}$ ( -1.3 vs. -1.6 vs. $-0.5 \%)$; semaglutide 0.5 and $1.0 \mathrm{mg}$ achieved a greater body weight reduction vs. sitagliptin $100 \mathrm{mg}$ (-4.3 vs. $-6.1 \mathrm{vs} .-1.9 \mathrm{~kg}$ ) Semaglutide $1.0 \mathrm{mg}$ achieved a greater $\mathrm{HbA} 1 \mathrm{c}$ reduction vs. exenatide once weekly $2.0 \mathrm{mg}$ (-1.5 vs. $-0.9 \%)$; semaglutide $1.0 \mathrm{mg}$ achieved a greater body weight reduction vs. exenatide once weekly $2.0 \mathrm{mg}(-5.6 \mathrm{vs} .-1.9 \mathrm{~kg})$

Semaglutide 0.5 and $1.0 \mathrm{mg}$ achieved a greater $\mathrm{HbA} 1 \mathrm{c}$ reduction vs. insulin glargine (-1.21 vs. -1.64 vs. $-0.83 \%$ ); semaglutide 0.5 and $1.0 \mathrm{mg}$ achieved a greater body weight reduction vs insulin glargine $(-3.5$ vs. -5.2 vs. $+1.15 \mathrm{~kg})$

Semaglutide 0.5 and $1.0 \mathrm{mg}$ achieved a greater $\mathrm{HbA} 1 \mathrm{c}$ reduction vs. placebo (-1.4 vs. -1.8 vs. $-0.1 \%$ ); semaglutide 0.5 and $1.0 \mathrm{mg}$ achieved a greater body weight reduction vs. placebo (-3.7 vs. -6.4 vs. $-1.4 \mathrm{~kg}$ )

Semaglutide arm had a lower primary outcome (first occurrence of cardiovascular death, nonfatal myocardial infarction or nonfatal stroke) occurrence vs. placebo (6.6 vs. 8.9\%); semaglutide arm had lower rates of new or worsening nephropathy vs. placebo (3.8 vs. 6.1\%); semaglutide arm had a higher incidence of retinopathy complications vs. placebo (3.0 vs. $1.8 \%$ )

Semaglutide $0.5 \mathrm{mg}$ achieved a greater $\mathrm{HbA} 1 \mathrm{c}$ reduction vs. dulaglutide $0.75 \mathrm{mg}$ (-1.5 vs. $-1.1 \%$ ); semaglutide $1.0 \mathrm{mg}$ achieved a greater HbA1c reduction vs. dulaglutide $1.5 \mathrm{mg}$ (-1.8 vs. $-1.4 \%$ ); semaglutide $0.5 \mathrm{mg}$ achieved a greater weight reduction vs. dulaglutide $0.75 \mathrm{mg}$ (-4.6 vs. $-2.3 \mathrm{~kg}$ ); semaglutide $1.0 \mathrm{mg}$ achieved a greater body weight reduction vs. dulaglutide $1.5 \mathrm{mg}$ (-6.5 vs. $-3.0 \mathrm{~kg}$ )

Semaglutide $1.0 \mathrm{mg}$ achieved a greater $\mathrm{HbA} 1 \mathrm{c}$ reduction vs.

canagliflozin $300 \mathrm{mg}$ (-1.5 vs. $-1.0 \%$ ); semaglutide $1.0 \mathrm{mg}$ achieved a greater body weight reduction vs. canagliflozin $300 \mathrm{mg}$ $(-5.3$ vs. $-4.2 \mathrm{~kg})$

Semaglutide markedly reduced HbA1c when added to a SGLT-2 inhibitor vs. placebo ( -1.5 vs. $-0.1 \%)$; semaglutide markedly reduced body weight when added to a SGLT-2 inhibitor vs. placebo (-4.7 vs. $-0.9 \mathrm{~kg})$

Semaglutide $1.0 \mathrm{mg}$ had a greater $\mathrm{HbA} 1 \mathrm{c}$ reduction vs. liraglutide $1.2 \mathrm{mg}(-1.7$ vs. $-1.0 \%)$; semaglutide $1.0 \mathrm{mg}$ had a greater body weight reduction vs. liraglutide $1.2 \mathrm{mg}(-5.8 \mathrm{vs} .-1.9 \mathrm{~kg})$

T2DM, type 2 diabetes mellitus; HbA1c, glycated hemoglobin; SUSTAIN, Semaglutide Unabated Sustainability in Treatment of Type 2 Diabetes.

to exenatide-treated subjects (-5.6 vs. $-1.9 \mathrm{~kg}$; ETD $-3.78 \mathrm{~kg}$; $\mathrm{P}<0.0001$ ) (33). SUSTAIN-4 compared semaglutide vs. insulin glargine. Body weight loss was observed in semaglutide-treated subjects and at week 30 , a loss of $3.5 \mathrm{~kg}$ with semaglutide $0.5 \mathrm{mg}$ and $5.2 \mathrm{~kg}$ with semaglutide $1.0 \mathrm{mg}$, compared to a weight gain of $1.15 \mathrm{~kg}$ with insulin glargine was observed (34). This result came with no surprise given the appetite-reducing effects of GLP-1 and the anabolic effects of insulin. When added to basal insulin, in patients with T2DM with or without metformin treatment, semaglutide produced a significant body weight 
reduction vs. placebo according to the results of SUSTAIN-5 (-3.7 kg with semaglutide $0.5 \mathrm{mg}$ vs. $-6.4 \mathrm{~kg}$ with semaglutide $1.0 \mathrm{mg}$ vs. $-1.4 \mathrm{~kg}$ with placebo; $\mathrm{P}$ for both doses of semaglutide vs. placebo <0.0001) (35). In SUSTAIN-7, semaglutide was superior to dulaglutide regarding body weight reduction properties. Semaglutide $0.5 \mathrm{mg}$ achieved a weight reduction of 4.6 vs. $2.3 \mathrm{~kg}$ with dulaglutide $0.75 \mathrm{mg}$. Furthermore, an even greater difference was observed between semaglutide $1.0 \mathrm{mg}$ vs. dulaglutide $1.5 \mathrm{mg}$ (-6.5 vs. $-3.0 \mathrm{~kg}$ ) (36).

Semaglutide was superior to canagliflozin in reducing body weight (ETD, $-1.06 \mathrm{~kg}$; $\mathrm{P}<0.0029$ ) in SUSTAIN-8 (37). A sub-study of SUSTAIN-8 compared the effects of semaglutide $1.0 \mathrm{mg}$ and once-daily canagliflozin $300 \mathrm{mg}$ on body composition in individuals with T2DM uncontrolled with metformin. The results indicated no significant differences between semaglutide and canagliflozin regarding changes in body composition (40). In SUSTAIN-9, adding semaglutide to a SGLT-2 inhibitor achieved significant improvements in body weight reduction compared to placebo (ETD, $-3.81 \mathrm{~kg}$; $\mathrm{P}<0.0001$ ) (38). Given the positive outcomes that were obtained when adding semaglutide to canagliflozin, it is indicated that combining a GLP-1 RA and a SGLT-2 inhibitor may provide an additive effect in improving glycemic control and body weight reduction and also in reducing cardiovascular risk and renal impairment.

Patients receiving semaglutide in SUSTAIN-10 had a superior reduction in body weight compared with the liraglutide-treated group (ETD, $-3.83 \mathrm{~kg}$; P<0.0001) (39). Semaglutide was studied as a possible chronic weight management drug in non-diabetic obesity. A randomized, double-blinded, placebo-controlled trial performed on 957 individuals without diabetes was performed to evaluate the safety and efficacy of semaglutide in comparison with liraglutide and placebo in promoting weight loss. Participants received semaglutide at dosages ranging from 0.05 to $0.4 \mathrm{mg}$ or liraglutide $3.0 \mathrm{mg}$ as once-daily subcutaneous injections. The estimated mean loss for the $0.4 \mathrm{mg}$ semaglutide group was -13.8 vs. $-2.3 \%$ with placebo. Mean body weight reductions with $\geq 0.2 \mathrm{mg}$ semaglutide vs. liraglutide were significant (-13.8 to -11.2 vs. $-7.8 \%$ ) (41). A double-blinded randomized clinical trial, which included 1,961 adults without T2DM with a body mass index of at least 30 or at least $27 \mathrm{~kg} / \mathrm{m}^{2}$ with $\geq 1$ weight-related coexisting comorbidity, investigated the role of $2.4 \mathrm{mg}$ subcutaneous semaglutide vs. placebo in addition to lifestyle interventions. At week 68, the mean body weight change was highly significant in the semaglutide group vs. the placebo group (-14.9 vs. $-2.4 \%$; ETD, $-12.4 \%$; $\mathrm{P}<0.001)$. A weight reduction of at least $5 \%$ was achieved by $86.4 \%$ of the subjects in the semaglutide group vs. $31.5 \%$ in the placebo group. A $10 \%$ weight reduction was achieved by $69.1 \%$ of subjects in the semaglutide group vs. $12.0 \%$ of subjects in the placebo group. A $15 \%$ weight reduction occurred in $50.5 \%$ of patients of the semaglutide group vs. $4.9 \%$ in the placebo group (42). Given the proven benefits of semaglutide in managing chronic excess weight and its good safety profile, the Food and Drug Administration recently approved the use of semaglutide $2.4 \mathrm{mg} /$ once-weekly as an add-on-therapy to lifestyle modifications in adults with obesity or overweight with at least one weight-related comorbidity (43). Therefore, semaglutide became the second GLP-1 RA besides liraglutide that may be used in managing non-diabetic excess weight. The Food and Drug Administration approval was based on the results from the Semaglutide Treatment Effect in People with Obesity (STEP) program, which consisted of four phase III clinical trials. A summary of the STEP program is illustrated in Table III $(42,44-46)$.

Oral semaglutide: Blood glucose and body weight benefits. Oral semaglutide (Rybelsus), the first oral GLP-1 RA, was studied in 10 phase IIIa clinical trials as part of the PIONEER program. PIONEER-1 was a 26-week randomized, double-blinded clinical trial that compared the efficacy and safety of oral semaglutide $(3,7$ or $14 \mathrm{mg}$ ) as monotherapy with placebo in subjects with T2DM managed by lifestyle interventions. It was demonstrated that oral semaglutide at all doses was superior to the placebo in improving $\mathrm{HbA} 1 \mathrm{c}$ (ranging from -0.6 to $-1.1 \%$ ) and in body weight reduction (14 mg dose) (47). Results from PIONEER-2 suggested that oral semaglutide $14 \mathrm{mg}$ was superior in reducing $\mathrm{HbA} 1 \mathrm{c}$ compared with empagliflozin $25 \mathrm{mg}$ in a 52-week trial (1.3 vs. 0.9\%; ETD -0.4\%; P<0.0001). Furthermore, at week 52, oral semaglutide achieved an average weight reduction of 4.7 vs. $3.8 \mathrm{~kg}$ with empagliflozin, rendering oral semaglutide significantly more effective ( $\mathrm{P}=0.0114)$ (48). The PIONEER-4 clinical trial demonstrated that oral semaglutide (14 mg) was non-inferior in decreasing HbAlc to subcutaneous liraglutide $(1.8 \mathrm{mg})$ at week 26 (ETD, -0.1\%; $\mathrm{P}<0.0001)$ and superior to placebo (ETD, -1.1\%; P<0.0001). Furthermore, oral semaglutide achieved a greater weight reduction than liraglutide and placebo (-4.4 vs. -3.1 vs. $0.5 \mathrm{~kg}$; ETD, $-1.2 \mathrm{~kg}$ vs. liraglutide and $-3.8 \mathrm{~kg}$ vs. placebo; $\mathrm{P}=0.0003$ and $\mathrm{P}<0.0001$, respectively) (49).

The PIONEER 10 clinical trial investigated the efficacy and safety of oral semaglutide vs. dulaglutide in Japanese patients with uncontrolled T2DM. Oral once-daily semaglutide (14 mg) achieved a significant HbA1c reduction vs. once-weekly dulaglutide $(0.75 \mathrm{mg})$ (ETD, $-0.3 \%$; $\mathrm{P}=0.0170)$. Furthermore, oral semaglutide significantly reduced body weight vs. dulaglutide (ETD, -2.6 kg for oral semaglutide $14 \mathrm{vs} .0 .75 \mathrm{mg}$ dulaglutide; $\mathrm{P}<0.0001)(50)$.

Cardiovascular benefits of semaglutide. The SUSTAIN-6 clinical trial investigated the cardiovascular safety of once-weekly subcutaneous administration of semaglutide. The primary outcome composite (first occurrence of cardiovascular death, nonfatal myocardial infarction or nonfatal stroke) occurred in $6.6 \%$ in the semaglutide group vs. $8.9 \%$ in the placebo group $(\mathrm{P}<0.0001$ for noninferiority). Mortality rates from cardiovascular causes were similar among the studied groups, while the semaglutide group had an advantage regarding lower rates of new or worsening nephropathy [3.8 vs. $6.1 \%$, hazard ratio $(\mathrm{HR})=0.64, \mathrm{P}<0.01]$ (51). Furthermore, by improving glucose metabolism, GLP-1 RAs are able to prevent the development of macroalbuminuria and also maintain an adequate glomerular filtration rate, and are an efficient and safe option in diabetic nephropathy (52). However, semaglutide-treated subjects had a higher incidence of retinopathy complications vs. placebo $(\mathrm{P}=0.02)$ (51). Recently published results demonstrated that semaglutide improved health-related quality of life vs. placebo in patients with T2DM with high cardiovascular risk in the 
Table III. Summary of clinical trials from the STEP program.

\begin{tabular}{|c|c|c|c|}
\hline Clinical trial & Design & Aim & Main results \\
\hline STEP-1 & $\begin{array}{l}\text { 68-week randomized, } \\
\text { double-blind, multicentre, } \\
\text { placebo-controlled }\end{array}$ & $\begin{array}{l}\text { To investigate the efficacy and safety of } \\
\text { semaglutide } 2.4 \mathrm{mg} / \text { once-weekly vs. } \\
\text { placebo in } 1,961 \text { adults with obesity or } \\
\text { overweight with comorbidities }\end{array}$ & $\begin{array}{l}\text { Semaglutide } 2.4 \mathrm{mg} \text { achieved a weight } \\
\text { loss of } 14.9 \text { vs. } 2.4 \% \text { with placebo; } \\
86.4 \% \text { of the semaglutide } 2.4 \mathrm{mg} \text { group } \\
\text { achieved a weight loss of } \geq 5 \mathrm{vs.} 31.5 \% \\
\text { with placebo }\end{array}$ \\
\hline STEP-2 & $\begin{array}{l}\text { 68-week randomized, } \\
\text { double-blind, multicentre, } \\
\text { placebo-controlled }\end{array}$ & $\begin{array}{l}\text { To compare the efficacy and safety of } \\
\text { semaglutide } 2.4 \mathrm{mg} / \text { once-weekly vs. } \\
\text { semaglutide } 1.0 \mathrm{mg} / \text { once-weekly vs. } \\
\text { placebo in } 1,210 \text { adults with T2DM and } \\
\text { obesity or overweight with comorbidities }\end{array}$ & $\begin{array}{l}\text { Semaglutide } 2.4 \mathrm{mg} \text { achieved a } \\
\text { weight loss of } 9.6 \mathrm{vs} .7 .0 \% \text { with } \\
\text { semaglutide } 1.0 \mathrm{mg} \text { vs. } 3.4 \% \text { with } \\
\text { placebo; } 68.8 \% \text { of semaglutide } \\
2.4 \mathrm{mg} \text { group achieved a weight loss } \\
\text { of } \geq 5 \text { vs. } 28.5 \% \text { with placebo }\end{array}$ \\
\hline STEP-3 & $\begin{array}{l}\text { 68-week randomized, } \\
\text { double-blind, multicentre, } \\
\text { placebo-controlled }\end{array}$ & $\begin{array}{l}\text { To investigate the efficacy and safety of } \\
\text { semaglutide } 2.4 \mathrm{mg} / \text { once-weekly vs. } \\
\text { placebo in combination with intensive } \\
\text { behavioral treatment in } 611 \text { adults with } \\
\text { obesity or overweight with comorbidities }\end{array}$ & $\begin{array}{l}\text { Semaglutide } 2.4 \mathrm{mg} \text { achieved a } \\
\text { weight loss of } 16.0 \mathrm{vs} .5 .7 \% \text { with } \\
\text { placebo; } 86.6 \% \text { of semaglutide } \\
2.4 \mathrm{mg} \text { group achieved a weight loss } \\
\text { of } \geq 5 \mathrm{vs} .47 .6 \% \text { with placebo }\end{array}$ \\
\hline STEP-4 & $\begin{array}{l}\text { 68-week randomized, } \\
\text { double-blind, multicentre, } \\
\text { placebo-controlled }\end{array}$ & $\begin{array}{l}\text { To investigate the efficacy and safety of } \\
\text { semaglutide } 2.4 \mathrm{mg} / \text { once-weekly vs. } \\
\text { placebo in } 902 \text { adults with obesity or } \\
\text { overweight }\end{array}$ & $\begin{array}{l}\text { After } 20 \text { weeks run-in, } 803 \text { adults } \\
\text { reached the target dose of semaglutide } \\
2.4 \mathrm{mg} \text { and were randomized to } \\
\text { continued treatment or placebo for } \\
48 \text { weeks; after } 48 \text { weeks, semaglutide } \\
2.4 \mathrm{mg} \text { achieved an additional weight } \\
\text { loss of } 7.9 \text { vs. } 6.9 \% \text { with placebo; after } \\
68 \text { weeks, semaglutide } 2.4 \text { mg achieved } \\
\text { a total weight loss of } 17.4 \%\end{array}$ \\
\hline
\end{tabular}

T2DM, type 2 diabetes mellitus; STEP, Semaglutide Treatment Effect in People with Obesity.

SUSTAIN-6 trial, possibly explained by the reduction of HbA1c and weight loss (53).

PIONEER-6 investigated the cardiovascular outcomes for oral semaglutide in subjects with T2DM and with high cardiovascular risk in an event-driven, randomized, double-blinded, placebo-controlled trial. Oral semaglutide was non-inferior to placebo regarding cardiovascular safety, with major cardiovascular events occurring in $3.8 \%$ of the oral semaglutide-treated subjects vs. $4.8 \%$ in the placebo group $(\mathrm{HR}=0.79 ; \mathrm{P}<0.001$ for non-inferiority) (54). The study did not have the statistical power to demonstrate superiority, as it was an event-driven trial. Death from cardiovascular causes occurred in $0.9 \%$ in the oral semaglutide group vs. $1.9 \%$ in the placebo group $(\mathrm{HR}=0.49)$ and nonfatal myocardial infarction occurred in $2.3 \%$ in the oral semaglutide group vs. $1.9 \%$ in the placebo group $(\mathrm{HR}=1.18)$, while nonfatal stroke occurred in $0.8 \%$ in the oral semaglutide group vs. $1.0 \%$ in the placebo group $(\mathrm{HR}=0.74)$. All-cause mortality was encountered in $1.4 \%$ in the oral semaglutide group vs. $2.8 \%$ in the placebo group $(\mathrm{HR}=0.51)(54)$.

Semaglutide and nonalcoholic fatty liver disease (NAFLD). NAFLD is a metabolic liver disease that has a broad spectrum of clinical presentation, ranging from simple steatosis to severe forms such as nonalcoholic steatohepatitis (NASH), cirrhosis and hepatocellular carcinoma (55). Similar to that of T2DM and obesity, the incidence of NAFLD is increasing worldwide. It is estimated that up to 70-80\% of patients with T2DM and/or obesity present with NAFLD $(56,57)$. T2DM is an important risk factor for the progression of NAFLD to more severe forms (58-60). The exact pathophysiological mechanisms which lead to NAFLD remain to be completely elucidated, but several proposed hypotheses include insulin resistance, environmental factors, polymorphisms, adipose tissue expandability and spleen mechanisms to promote liver fat accumulation (61). Currently, lifestyle changes are the primary tool in managing NAFLD, as to date, no pharmacological treatment has been approved.

GLP-1 RAs may be a potential therapeutic option given their benefits in T2DM and obesity, the two major drivers of NAFLD (62). In a systematic review published in 2020 by Lv et al (63), GLP-1 RAs were determined to improve liver enzymes and hepatic steatosis. A recently published metanalysis by Mantovani et al (64) investigated the published data of placebo-controlled, active-controlled or randomized controlled trials that evaluated the efficacy and safety of GLP-1 RAs in treating NAFLD or NASH in adults with or without T2DM. They revealed GLP-1 RAs to be efficient in 


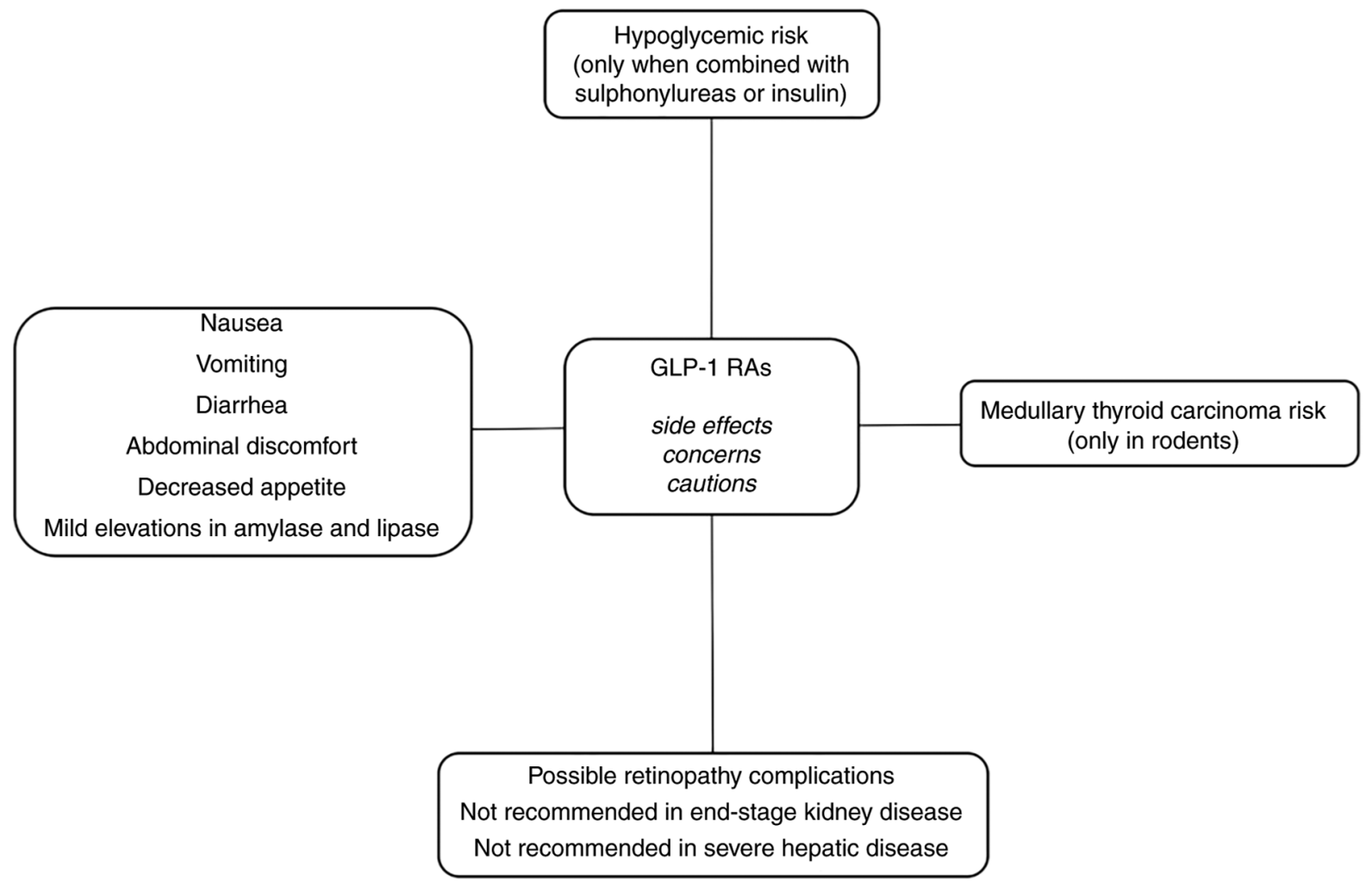

Figure 1. Side effects, cautions and concerns related to GLP-1 RAs. GLP-1 RAs, glucagon-like peptide 1 receptor agonists.

improving NAFLD, particularly liraglutide and semaglutide. A randomized, double-blinded, placebo-controlled, phase 2 trial compared daily semaglutide $(0.1,0.2$ and $0.4 \mathrm{mg})$ with placebo in patients with biopsy-confirmed NASH. NASH resolution without worsening of fibrosis was observed in $40 \%$ of cases in the semaglutide $0.1 \mathrm{mg}$ group, in $36 \%$ of cases in the semaglutide $0.2 \mathrm{mg}$ group and in $59 \%$ in the semaglutide $0.4 \mathrm{mg}$ group, compared with $17 \%$ of cases in the placebo group $(\mathrm{P}<0.001$, semaglutide $0.4 \mathrm{mg}$ vs. placebo). However, there was no significant improvement regarding the fibrosis stage between semaglutide $0.4 \mathrm{mg}$ and the placebo $(\mathrm{P}=0.48)(65)$.

\section{Semaglutide-side effects and cautions}

Semaglutide mainly shares the classically observed side effects of other GLP-1 RAs (Fig. 1).

Gastrointestinal side effects. The common side effects associated with GLP-1 RAs use are gastrointestinal reactions, mainly nausea, vomiting and diarrhea. During the SUSTAIN program that assessed safety parameters, the rate of discontinuation due to adverse events was low (5-13\%), with SUSTAIN-6 reporting a higher discontinuation rate (almost 20\%). The major reasons for the discontinuation were gastrointestinal adverse events (31-36). Nausea occurred in $17.0 \%$, diarrhea in $12.2 \%$ and vomiting in $6.4 \%$ of patients treated with semaglutide $0.5 \mathrm{mg}$. As for patients treated with semaglutide $1.0 \mathrm{mg}$, nausea occurred in $19.9 \%$, diarrhea in $13.3 \%$ and vomiting in $8.4 \%$ of cases $(66,67)$. Semaglutide has a similar gastrointestinal safety profile as other GLP-1 Ras $(68,69)$. A metanalysis from 2018 that included nine phase III randomized controlled trials and
9,773 subjects highlighted that semaglutide did not increase the risk of any adverse events, hypoglycemia or pancreatitis, but had a higher risk of gastrointestinal reactions (mainly nausea, vomiting, diarrhea, abdominal discomfort and decreased appetite) when compared to other therapies [relative risk $(\mathrm{RR})=1.98$; $\mathrm{P}<0.001]$ (70). Given that the occurrence of gastrointestinal reactions is the main reason for treatment discontinuation, a titration regimen is recommended for semaglutide, starting with $0.25 \mathrm{mg}$ once-weekly for 4 weeks, increasing the dose to $0.5 \mathrm{mg}$ once-weekly for at least 4 weeks. If a higher dose is required to achieve proper glycemic control, the dose may then be increased to $1.0 \mathrm{mg}$ once-weekly, assuming the tolerance is adequate. For oral semaglutide, the initial dose is $3 \mathrm{mg}$ /day for the first month, then the dose should be increased to $7 \mathrm{mg} /$ day for at least another month (the dose may be increased up to $14 \mathrm{mg} /$ day in the case of poor glycemic control).

Risk of hypoglycemia. The frequency of hypoglycemia was observed to be usually low (1-2\%) when semaglutide was not combined with insulin or sulphonylureas $(31,32,36,71)$. However, when added to sulphonylureas or insulin, hypoglycemia had higher frequencies (4-10\%) (33-35,71). Shi et al (70) observed no increased risk of hypoglycemia with semaglutide when compared to other therapies $(\mathrm{RR}=1.07 ; \mathrm{P}=0.317)$.

Medullary thyroid carcinoma and pancreatitis concerns. Rodent studies have indicated an increased risk of developing medullary thyroid carcinoma following treatment with GLP-1 RAs, but without existing confirmation of these results in humans $(72,73)$. The SUSTAIN program suggested no elevation in calcitonin levels. However, GLP-1 RAs should 
not be used in individuals with a personal or family history of medullary thyroid carcinoma or multiple endocrine neoplasia type $2 \mathrm{~A}$ and $2 \mathrm{~B}(23,74)$. Concerns about pancreatitis in incretin-based therapy have been raised due to mild elevations in amylase and/or lipase levels (75). The risk of pancreatitis with semaglutide was not significantly higher when compared with other therapies ( 0.3 vs. $0.4 \%, \mathrm{RR}=0.82 ; \mathrm{P}=0.641)(70)$. In 2020, Abd El Aziz et al (76) published a metanalysis based on cardiovascular outcome trials and indicated no significant risk of acute pancreatitis or any malignant disease.

Ocular and renal effects. SUSTAIN-6 noted an increased risk of retinopathy complications (vitreous hemorrhage, blindness or conditions requiring treatment with an intravitreal agent or photocoagulation) in the semaglutide group vs. the placebo group ( 3.0 vs. $1.8 \%, \mathrm{HR}=1.76, \mathrm{P}=0.02)(51)$. On the contrary, SUSTAIN-1-5 and -7 did not report any similar results. One explanation for these observations may be the HbA1c levels at baseline and the rapidity of reduction of $\mathrm{HbAlc}$, considering that rapid improvement in glucose control has been associated with aggravated diabetic retinopathy (77-79). No dose adjustment is required based on age or in patients with mild, moderate or severe renal or hepatic impairment; however, it is not recommended in patients with end-stage kidney disease and experience in severe hepatic disease is limited $(66,67)$.

\section{Future considerations}

Weight loss induced by GLP-1 RAs is usually observed after long-term treatment. GLP-1 RAs promote weight loss mainly by reducing appetite, thus reducing food consumption and by increasing satiety. Treatment adherence is important, as well as lifestyle changes, which include dietary caloric deficit and increased physical activity. It was observed that a higher dose of GLP-1 RA is associated with a higher chance to obtain a higher weight reduction. However, weight reduction usually lasts as long as the treatment is continued, with near-baseline weight values returning within months of discontinuation of pharmacological treatment as reported by Kelly et al (80).

Semaglutide is the second GLP-1 RA that may be safely and efficiently used in non-diabetic individuals with excess weight, providing a new milestone in the pharmacological treatment of obesity. Furthermore, oral semaglutide, given its posology, may provide higher attractiveness and better treatment adherence, and thus, future research into the use of oral semaglutide in non-diabetic obese patients may provide novel insight and an effective and safe weight-loss method. Combination therapy with semaglutide is also being studied. A randomized, placebo-controlled, multiple ascending dose, phase Ib trial investigated the combination of semaglutide $2.4 \mathrm{mg}$ with cagrilintide, a long-acting amylin analogue. Concomitant treatment with cagrilintide and semaglutide was well tolerated and produced a greater weight loss than semaglutide alone (81). Further studies are required to assess variable combination options with semaglutide to provide novel treatments for long-term weight management.

The cardiovascular safety of semaglutide was assessed in SUSTAIN-6 for once-weekly subcutaneous formulation and in PIONEER- 6 for the oral formulation, as discussed previously. A Heart Disease Study of Semaglutide in Patients with Type 2 Diabetes (SOUL) will bring additional data regarding the cardiovascular outcomes with oral semaglutide vs. placebo $(82,83)$. Semaglutide, as with other agents from the GLP-1 RAs drug class, reduces the risk of cardiovascular events in high-risk patients. The American Diabetes Association currently recommends the use of GLP-1 RAs as part of the antidiabetic treatment in patients with T2DM with atherosclerotic cardiovascular disease or established kidney disease (10). The positive effects of GLP-1 RAs on cardiovascular function may be explained by the beneficial effects of this drug class on glucose metabolism, body weight and blood pressure. The exact mechanisms of how GLP-1 RAs provide cardiovascular benefits remain to be elucidated in future research. Furthermore, long-term studies are required to investigate the potential additive effects on the cardiovascular and renal function of the combination between a GLP-1 RA and an SGLT-2 inhibitor.

Semaglutide achieved promising results in improving NAFLD. Larger randomized clinical trials are required to confirm its applicability in NAFLD. Furthermore, clinicians should focus on preventing the development of NAFLD by promoting a healthy lifestyle, particularly in individuals suffering from T2DM and obesity who are at high risk of developing steatohepatitis.

\section{Conclusions}

The present review highlighted the benefits of semaglutide not only as an antidiabetic agent but also as a drug with effective weight reduction properties. Clinicians should be aware that semaglutide therapy is one of the most modern methods of treatment for patients with T2DM and obesity, and has recently been approved for the treatment of non-diabetic excess weight. Semaglutide (both subcutaneous and oral formulation) is an efficient and safe therapeutic approach for diabesity, with an excellent cardiovascular profile. Regarding the microvascular complications, potential for reducing diabetic nephropathy was noted, with concerns regarding a possible worsening of diabetic retinopathy, thus requiring further studies for clarification. The perspective of oral semaglutide as an antiobesity drug is promising and may be associated with increased treatment adherence. There is still increased potential for further research to enhance and optimize the use of semaglutide in diabesity and non-diabetic obesity to reduce morbidity and mortality associated with these metabolic disorders and to improve quality of life.

\section{Acknowledgements}

Not applicable.

\section{Funding}

No funding was received.

\section{Availability of data and materials}

Not applicable. 


\section{Authors' contributions}

MCT and RAT contributed to the design and conception of the study. RAT and $\mathrm{CN}$ searched and consulted the relevant literature, selected the studies/data and wrote the first draft of the manuscript. MCT, AV and IT substantially added contributions by revising and editing the final manuscript. All authors have read and approved the final version of the manuscript. Data authentication is not applicable.

\section{Ethics approval and consent to participate}

Not applicable.

\section{Patient consent for publication}

Not applicable.

\section{Competing interests}

The authors declare that they have no competing interests.

\section{References}

1. Hasanzad M, Sarhangi N, Nikfar S, Ostad SN and Aghaei Meybodi HR: A narrative review of current trends in liraglutide: Insights into the unmet needs in management of type 2 diabetes and obesity. J Diabetes Metab Disord 19: 1863-1872, 2020.

2. World Health Organization (WHO): Obesity and Overweight, 2020. https://www.who.int/news-room/fact-sheets/detail/obesityand-overweight. Accessed April 21, 2021

3. Gadde KM, Martin CK, Berthoud HR and Heymsfield SB: Obesity: Pathophysiology and management. J Am Coll Cardiol 71: 69-84, 2018

4. Sims EA, Danforth E Jr, Horton ES, Bray GA, Glennon JA and Salans LB: Endocrine and metabolic effects of experimental obesity in man. Recent Prog Horm Res 29: 457-496, 1973.

5. International Diabetes Federation: IDF Diabetes Atlas-9th edition. http://www.diabetesatlas.org/(2019). Accessed April 21, 2021.

6. Zhang PY: Cardiovascular disease in diabetes. Eur Rev Med Pharmacol Sci 18: 2205-2214, 2014.

7. Cercato $\mathrm{C}$ and Fonseca FA: Cardiovascular risk and obesity. Diabetol Metab Syndr 11: 74, 2019.

8. Apovian CM, Okemah J and O'Neil PM: Body weight considerations in the management of type 2 diabetes. Adv Ther 36: 44-58, 2019.

9. American Diabetes Association: 8. Obesity management for the treatment of type 2 diabetes: Standards of medical care in diabetes-2021. Diabetes Care 44 (Suppl 1): S100-S110, 2021.

10. American Diabetes Association: 9. Pharmacologic approaches to glycemic treatment: Standards of medical care in diabetes-2021. Diabetes Care 44 (Suppl 1): S111-S124, 2021.

11. Herrmann C, Göke R, Richter G, Fehmann HC, Arnold R and Göke B: Glucagon-like peptide-1 and glucose-dependent insulin-releasing polypeptide plasma levels in response to nutrients. Digestion 56: 117-126, 1995.

12. Müller TD, Finan B, Bloom SR, D'Alessio D, Drucker DJ, Flatt PR, Fritsche A, Gribble F, Grill HJ, Habener JF, et al: Glucagon-like peptide 1 (GLP-1). Mol Metab 30: 72-130, 2019.

13. Holst JJ: The physiology of glucagon-like peptide 1. Physiol Rev 87: 1409-1439, 2007.

14. Drucker DJ: Glucagon-like peptide-1 and the islet beta-cell: Augmentation of cell proliferation and inhibition of apoptosis. Endocrinology 144: 5145-5148, 2003.

15. Lee YS and Jun HS: Anti-diabetic actions of glucagon-like peptide-1 on pancreatic beta-cells. Metabolism 63: 9-19, 2014.

16. Tang-Christensen M, Vrang N and Larsen PJ: Glucagon-like peptide containing pathways in the regulation of feeding behaviour. Int J Obes Relat Metab Disord 25 (Suppl 5): S42-S47, 2001

17. Rinaman L: Ascending projections from the caudal visceral nucleus of the solitary tract to brain regions involved in food intake and energy expenditure. Brain Res 1350: 18-34, 2010.
18. Chilton R, Wyatt J, Nandish S, Oliveros R and Lujan M: Cardiovascular comorbidities of type 2 diabetes mellitus: Defining the potential of glucagonlike peptide-1-based therapies. Am J Med 124 (Suppl): S35-S53, 2011

19. Nikolaidis LA, Mankad S, Sokos GG, Miske G, Shah A, Elahi D and Shannon RP: Effects of glucagon-like peptide-1 in patients with acute myocardial infarction and left ventricular dysfunction after successful reperfusion. Circulation 109: 962-965, 2004.

20. Meier JJ, Gethmann A, Götze O, Gallwitz B, Holst JJ, Schmidt WE and Nauck MA: Glucagon-like peptide 1 abolishes the postprandial rise in triglyceride concentrations and lowers levels of non-esterified fatty acids in humans. Diabetologia 49: 452-458, 2006.

21. Gutzwiller JP, Tschopp S, Bock A, Zehnder CE, Huber AR, Kreyenbuehl M, Gutmann H, Drewe J, Henzen C, Goeke B and Beglinger C: Glucagon-like peptide 1 induces natriuresis in healthy subjects and in insulin-resistant obese men. J Clin Endocrinol Metab 89: 3055-3061, 2004.

22. Nauck MA and Meier JJ: Management of endocrine disease: Are all GLP-1 agonists equal in the treatment of type 2 diabetes? Eur J Endocrinol 181: R211-R234, 2019.

23. Nauck MA, Quast DR, Wefers J and Meier JJ: GLP-1 receptor agonists in the treatment of type 2 diabetes-state-of-the-art. Mol Metab 46: 101102, 2021

24. Iepsen EW, Torekov SS and Holst JJ: Liraglutide for type 2 diabetes and obesity: A 2015 update. Expert Rev Cardiovasc Ther 13: 753-767, 2015.

25. Pandey A, Chawla S and Guchhait P: Type-2 diabetes: Current understanding and future perspectives. IUBMB Life 67: 506-513, 2015.

26. Paley CA and Johnson MI: Abdominal obesity and metabolic syndrome: Exercise as medicine? BMC Sports Sci Med Rehabil 10: 7, 2018.

27. Siddiqui S: Obesity and diabetes: Interrelationship. Adv Obes Weight Manag Control 8: 155-158, 2018.

28. Nicola P, Ardeleanu E, Gadau C, Dorobantu M, Darabont R, Tilea I, Varga A, Folescu R, Zamfir AS, Boanca M, et al: Evaluation of biochemical and clinical parametres of hypertension with type 2 diabetes mellitus. Rev Chim 69: 2402-2406, 2018.

29. Nolen-Doerr E, Stockman MC and Rizo I: Mechanism of glucagon-like peptide 1 improvements in type 2 diabetes mellitus and obesity. Curr Obes Rep 8: 284-291, 2019.

30. Hinnen D: Glucagon-like peptide 1 receptor agonists for type 2 diabetes. Diabetes Spectr 30: 202-210, 2017.

31. Sorli C, Harashima SI, Tsoukas GM, Unger J, Karsbøl JD, Hansen T and Bain SC: Efficacy and safety of once-weekly semaglutide monotherapy versus placebo in patients with type 2 diabetes (SUSTAIN 1): A double-blind, randomised, placebo-controlled, parallel-group, multinational, multicentre phase 3a trial. Lancet Diabetes Endocrinol 5: 251-260, 2017.

32. Ahrén B, Masmiquel L, Kumar H, Sargin M, Karsbøl JD, Jacobsen SH and Chow F: Efficacy and safety of once-weekly semaglutide versus once-daily sitagliptin as an add-on to metformin, thiazolidinediones, or both, in patients with type 2 diabetes (SUSTAIN 2): A 56-week, double-blind, phase 3a, randomised trial. Lancet Diabetes Endocrinol 5: 341-354, 2017.

33. Ahmann AJ, Capehorn M, Charpentier G, Dotta F, Henkel E, Lingvay I, Holst AG, Annett MP and Aroda VR: Efficacy and safety of once-weekly semaglutide versus exenatide ER in subjects with type 2 diabetes (SUSTAIN 3): A 56-week, open-label, randomized clinical trial. Diabetes Care 41: 258-266, 2018.

34. Aroda VR, Bain SC, Cariou B, Piletič M, Rose L, Axelsen M, Rowe E and DeVries JH: Efficacy and safety of once-weekly semaglutide versus once-daily insulin glargine as add-on to metformin (with or without sulfonylureas) in insulin-naive patients with type 2 diabetes (SUSTAIN 4): A randomised, open-label, parallel-group, multicentre, multinational, phase $3 \mathrm{a}$ trial. Lancet Diabetes Endocrinol 5: 355-366, 2017.

35. Rodbard HW, Lingvay I, Reed J, de la Rosa R, Rose L, Sugimoto D, Araki E, Chu PL, Wijayasinghe N and Norwood P: Semaglutide added to basal insulin in type 2 diabetes (SUSTAIN 5): A randomized, controlled trial. J Clin Endocrinol Metab 103: 2291-2301, 2018

36. Pratley RE, Aroda VR, Lingvay I, Lüdemann J, Andreassen C, Navarria A and Viljoen A; SUSTAIN 7 investigators: Semaglutide versus dulaglutide once weekly in patients with type 2 diabetes (SUSTAIN 7): A randomised, open-label, phase 3b trial. Lancet Diabetes Endocrinol 6: 275-286, 2018 
37. Lingvay I, Catarig AM, Frias JP, Kumar H, Lausvig NL, le Roux CW, Thielke D, Viljoen A and McCrimmon RJ: Efficacy and safety of once-weekly semaglutide versus daily canagliflozin as add-on to metformin in patients with type 2 diabetes (SUSTAIN 8): A double-blind, phase 3b, randomised controlled trial. Lancet Diabetes Endocrinol 7: 834-844, 2019.

38. Zinman B, Bhosekar V, Busch R, Holst I, Ludvik B, Thielke D, Thrasher J, Woo V and Philis-Tsimikas A: Semaglutide once weekly as add-on to SGLT-2 inhibitor therapy in type 2 diabetes (SUSTAIN 9): A randomised, placebo-controlled trial. Lancet Diabetes Endocrinol 7: 356-367, 2019.

39. Capehorn MS, Catarig AM, Furberg JK, Janez A, Price HC, Tadayon S, Vergès B and Marre M: Efficacy and safety of once-weekly semaglutide $1.0 \mathrm{mg}$ vs once-daily liraglutide $1.2 \mathrm{mg}$ as add-on to 1-3 oral antidiabetic drugs in subjects with type 2 diabetes (SUSTAIN 10). Diabetes Metab 46: 100-109, 2020.

40. McCrimmon RJ, Catarig AM, Frias JP, Lausvig NL, le Roux CW, Thielke D and Lingvay I: Effects of once-weekly semaglutide vs once-daily canagliflozin on body composition in type 2 diabetes: A substudy of the SUSTAIN 8 randomised controlled clinical trial. Diabetologia 63: 473-485, 2020.

41. O'Neil PM, Birkenfeld AL, McGowan B, Mosenzon O, Pedersen SD, Wharton S, Carson CG, Jepsen CH, Kabisch M and Wilding JPH: Efficacy and safety of semaglutide compared with liraglutide and placebo for weight loss in patients with obesity: A randomised, double-blind, placebo and active controlled, dose-ranging, phase 2 trial. Lancet 392: 637-649, 2018.

42. Wilding JPH, Batterham RL, Calanna S, Davies M, Van Gaal LF, Ling vay I, McGowan BM, Rosenstock J, Tran MTD, Wadden TA, et al: Once-weekly semaglutide in adults with overweight or obesity. N Engl J Med 384: 989-1002, 2021.

43. U.S. Food and Drug Administration: FDA Approves New Drug Treatment for Chronic Weight Management: First Since 2014 https://www.fda.gov/news-events/press-announcements/fdaapproves-new-drug-treatment-chronic-weight-management-first2014. Accessed June 25, 2021.

44. Davies M, Færch L, Jeppesen OK, Pakseresht A, Pedersen SD Perreault L, Rosenstock J, Shimomura I, Viljoen A, Wadden TA, et al: Semaglutide $2.4 \mathrm{mg}$ once a week in adults with overweight or obesity, and type 2 diabetes (STEP 2): A randomised, double-blind, double-dummy, placebo-controlled, phase 3 trial. Lancet 397: 971-984, 2021.

45. Wadden TA, Bailey TS, Billings LK, Davies M, Frias JP, Koroleva A,Lingvay I, O'Neil PM, Rubino DM, Skovgaard D, et al: Effect of subcutaneous semaglutide vs placebo as an adjunct to intensive behavioral therapy on body weight in adults with overweight or obesity: The STEP 3 randomized clinical trial JAMA 325: 1403-1413, 2021.

46. Rubino D, Abrahamsson N, Davies M, Hesse D, Greenway FL, Jensen C, Lingvay I, Mosenzon O, Rosenstock J, Rubio MA, et al: Effect of continued weekly subcutaneous semaglutide vs placebo on weight loss maintenance in adults with overweight or obesity: The STEP 4 randomized clinical trial. JAMA 325: 1414-1425, 2021.

47. Aroda VR, Rosenstock J, Terauchi Y, Altuntas Y, Lalic NM, Morales Villegas EC, Jeppesen OK, Christiansen E, Hertz CL and Haluzík M; PIONEER 1 Investigators: PIONEER 1: Randomized clinical trial of the efficacy and safety of oral semaglutide monotherapy in comparison with placebo in patients with type 2 diabetes. Diabetes Care 42: 1724-1732, 2019.

48. Rodbard HW, Rosenstock J, Canani LH, Deerochanawong C, Gumprecht J, Lindberg S $\varnothing$, Lingvay I, Søndergaard AL, Treppendahl MB and Montanya E; PIONEER 2 Investigators: Oral semaglutide versus empagliflozin in patients with type 2 diabetes uncontrolled on metformin: The PIONEER 2 trial. Diabetes Care 42: 2272-2281, 2019.

49. Pratley R, Amod A, Hoff ST, Kadowaki T, Lingvay I, Nauck M, Pedersen KB, Saugstrup T and Meier JJ; PIONEER 4 investigators: Oral semaglutide versus subcutaneous liraglutide and placebo in type 2 diabetes (PIONEER 4): A randomised, double-blind, phase 3a trial. Lancet 394: 39-50, 2019.

50. Yabe D, Nakamura J, Kaneto H, Deenadayalan S, Navarria A, Gislum $\mathrm{M}$ and Inagaki N; PIONEER 10 Investigators: Safety and efficacy of oral semaglutide versus dulaglutide in Japanese patients with type 2 diabetes (PIONEER 10): An open-label, randomised, active-controlled, phase 3a trial. Lancet Diabetes Endocrinol 8: 392-406, 2020.

51. Marso SP, Bain SC, Consoli A, Eliaschewitz FG, Jódar E, Leiter LA, Lingvay I, Rosenstock J, Seufert J, Warren ML, et al: Semaglutide and cardiovascular outcomes in patients with type 2 diabetes. N Engl J Med 375: 1834-1844, 2016.
52. Górriz JL, Soler MJ, Navarro-González JF, García-Carro C, Puchades MJ, D'Marco L, Martínez Castelao A, Fernández-Fernández B, Ortiz A, Górriz-Zambrano C, et al: GLP-1 receptor agonists and diabetic kidney disease: A call of attention to nephrologists. J Clin Med 9: 947, 2020.

53. Jódar E, Michelsen M, Polonsky W, Réa R, Sandberg A, Vilsbøll T, Warren M, Harring S, Ziegler U and Bain S: Semaglutide improves health-related quality of life versus placebo when added to standard of care in patients with type 2 diabetes at high cardiovascular risk (SUSTAIN 6). Diabetes Obes Metab 22: 1339-1347, 2020.

54. Husain M, Birkenfeld AL, Donsmark M, Dungan K, Eliaschewitz FG, Franco DR, Jeppesen OK, Lingvay I, Mosenzon O, Pedersen SD, et al: Oral semaglutide and cardiovascular outcomes in patients with type 2 diabetes. N Engl J Med 381: 841-851, 2019.

55. Hardy T, Oakley F, Anstee QM and Day CP: Nonalcoholic fatty liver disease: Pathogenesis and disease spectrum. Annu Rev Pathol 11: 451-496, 2016.

56. Non-alcoholic Fatty Liver Disease Study Group, Lonardo A, Bellentani S, Argo CK, Ballestri S, Byrne CD, Caldwell SH, Cortez-Pinto H, Grieco A, Machado MV, et al: Epidemiological modifiers of non-alcoholic fatty liver disease: Focus on high-risk groups. Dig Liver Dis 47: 997-1006, 2015.

57. Hazlehurst JM, Woods C, Marjot T, Cobbold JF and Tomlinson JW: Non-alcoholic fatty liver disease and diabetes. Metabolism 65: 1096-1108, 2016.

58. Mantovani A, Scorletti E, Mosca A, Alisi A, Byrne CD and Targher G: Complications, morbidity and mortality of nonalcoholic fatty liver disease. Metabolism 111S: 154170, 2020.

59. Lonardo A, Mantovani A, Lugari S and Targher G: Epidemiology and pathophysiology of the association between NAFLD and metabolically healthy or metabolically unhealthy obesity. Ann Hepatol 19: 359-366, 2020.

60. Younossi ZM: Non-alcoholic fatty liver disease-A global public health perspective. J Hepatol 70: 531-544, 2019.

61. Tarantino G, Citro V and Capone D: Nonalcoholic fatty liver disease: A challenge from mechanisms to therapy. J Clin Med 9: $15,2019$.

62. Tarantino G and Balsano C: Gastrointestinal peptides and nonalcoholic fatty liver disease. Curr Opin Endocrinol Diabetes Obes 27: 11-15, 2020.

63. Lv X, Dong Y, Hu L, Lu F, Zhou C and Qin S: Glucagon-like peptide-1 receptor agonists (GLP-1 RAs) for the management of nonalcoholic fatty liver disease (NAFLD): A systematic review. Endocrinol Diabetes Metab 3: e00163, 2020.

64. Mantovani A, Petracca G, Beatrice G, Csermely A, Lonardo A and Targher G: Glucagon-like peptide-1 receptor agonists for treatment of nonalcoholic fatty liver disease and nonalcoholic steatohepatitis: An updated meta-analysis of randomized controlled trials. Metabolites 11: 73, 2021.

65. Newsome PN, Buchholtz K, Cusi K, Linder M, Okanoue T, Ratziu V, Sanyal AJ, Sejling AS and Harrison SA; NN9931-4296 Investigators: A placebo-controlled trial of subcutaneous semaglutide in nonalcoholic steatohepatitis. N Engl J Med 384: 1113-1124, 2021.

66. European Medicines Agency: Ozempic: summary of product characteristics; 2018. https://www.ema.europa.eu/en/documents/ product-information/ozempic-epar-product-information_en.pdf. Accessed April 24, 2021.

67. Gomez-Peralta F and Abreu C: Profile of semaglutide in the management of type 2 diabetes: Design, development, and place in therapy. Drug Des Devel Ther 13: 731-738, 2019.

68. Trujillo JM, Nuffer W and Ellis SL: GLP-1 receptor agonists: A review of head-to-head clinical studies. Ther Adv Endocrinol Metab 6: 19-28, 2015.

69. Trujillo JM, Nuffer W and Smith BA: GLP-1 receptor agonists: An updated review of head-to-head clinical studies. Ther Adv Endocrinol Metab 12: 2042018821997320, 2021.

70. Shi FH, Li H, Cui M, Zhang ZL, Gu ZC and Liu XY: Efficacy and safety of once-weekly semaglutide for the treatment of type 2 diabetes: Protocol for a systematic review and meta-analysis. Medicine (Baltimore) 97: e0420, 2018.

71. Røder ME: Clinical potential of treatment with semaglutide in type 2 diabetes patients. Drugs Context 8: 212585, 2019.

72. Bjerre Knudsen L, Madsen LW, Andersen S, Almholt K, de Boer AS, Drucker DJ, Gotfredsen C, Egerod FL, Hegelund AC, Jacobsen $\mathrm{H}$, et al: Glucagon-like Peptide-1 receptor agonists activate rodent thyroid $\mathrm{C}$-cells causing calcitonin release and $\mathrm{C}$-cell proliferation. Endocrinology 151: 1473-1486, 2010. 
73. Prasad-Reddy L and Isaacs D: A clinical review of GLP-1 receptor agonists: Efficacy and safety in diabetes and beyond Drugs Context 4: 212283, 2015.

74. Sfairopoulos D, Liatis S, Tigas S and Liberopoulos E: Clinical pharmacology of glucagon-like peptide-1 receptor agonists. Hormones 17: 333-350, 2018.

75. Lando HM, Alattar M and Dua AP: Elevated amylase and lipase levels in patients using glucagonlike peptide-1 receptor agonists or dipeptidyl-peptidase-4 inhibitors in the outpatient setting. Endocr Pract 18: 472-477, 2012.

76. Abd El Aziz M, Cahyadi O, Meier JJ, Schmidt WE and Nauck MA: Incretin-based glucose-lowering medications and the risk of acute pancreatitis and malignancies: A meta-analysis based on cardiovascular outcomes trials. Diabetes Obes Metab 22: 699-704, 2020.

77. Diabetes Control and Complications Trial Research Group, Nathan DM, Genuth S, Lachin J, Cleary P, Crofford O, Davis M, Rand $L$ and Siebert C: The effect of intensive treatment of diabetes on the development and progression of long-term complications in insulin-dependent diabetes mellitus. N Engl J Med 329: 977-986, 1993.

78. Gorman DM, le Roux CW and Docherty NG: The effect of bariatric surgery on diabetic retinopathy: Good, bad, or both? Diabetes Metab J 40: 354-364, 2016.

79. American Diabetes Association: 14. management of diabetes in pregnancy: Standards of medical care in diabetes-2021. Diabetes Care 44 (Suppl 1): S200-S210, 2021.
80. Kelly AS, Auerbach P, Barrientos-Perez M, Gies I, Hale PM, Marcus C, Mastrandrea LD, Prabhu N and Arslanian S; NN8022-4180 Trial Investigators: A Randomized, controlled trial of liraglutide for adolescents with obesity. N Engl J Med 382: 2117-2128, 2020.

81. Enebo LB, Berthelsen KK, Kankam M, Lund MT, Rubino DM, Satylganova A and Lau DCW: Safety, tolerability, pharmacokinetics, and pharmacodynamics of concomitant administration of multiple doses of cagrilintide with semaglutide $2.4 \mathrm{mg}$ for weight management: A randomised, controlled, phase $1 \mathrm{~b}$ trial. Lancet 397: 1736-1748, 2021.

82. Nauck MA and Quast DR: Cardiovascular safety and benefits of semaglutide in patients with type 2 diabetes: Findings from SUSTAIN 6 and PIONEER 6. Front Endocrinol (Lausanne) 12: 645566, 2021.

83. ClinicalTrials.gov NCT03914326: A heart disease study of semaglutide in patients with type 2 diabetes (SOUL). https://clinicaltrials.gov/ct2/show/NCT03914326. Accessed July 10, 2021.

This work is licensed under a Creative Commons Attribution-NonCommercial-NoDerivatives 4.0 International (CC BY-NC-ND 4.0) License. 